процесса употребления языковых знаков в речи с четким акцентом на дидактически релевантном понятии - практика языка.

1. Арутюнова Н. Д. Речевой акт // Лингвистический энциклопедический словарь. - М.: Советская энциклопедия, 1990. - 682c.

2. Боева - Омелечко Н.Б. Краткий толковый словарь социолингвистических терминов. - М. Готика, 2004. - 60с.

3. Винокур Т.Г. Говорящий и слушающий. Варианты речевого поведения. М.; Российская академия наук. Институт русского языка-Скан, обработка, формат: Николай Савченко, 2018.

4. Остин Дж. Слово как действие // Новое в зарубежной лингвистике: теория речевых актов. Вып. XVII. - M., 1996. С. 27.

5. Серль Дж. Что такое речевой акт // Новое в зарубежной лингвистике: теория речевых актов. Вып. XVII. - M., 1996. С. 151-169.

6. Х Хабермас Юрген. Моральное сознание и коммуникативное действие СПб: Наука, 2001.-. 377с.

\title{
Алимханова М.X. \\ Метафорическая особенность средств выражения персуазивной коммуникации в немецком политическом дискурсе
}

ФГБОУ ВО «Чеченский государственный университет им. А.А. Кадырова»

(Россия, Грозный)

doi: 10.18411/trnio-12-2021-210

\section{Аннотация}

Данная статья посвящена исследованию персуазивной коммуникации в политическом дискурсе и ее метафорической особенности. Образ политического мира, созданного человеком, изначально антропоцентричен: этот мир строится в сознании человека, который находится в концептуализации политических реалий на своих представлениях об отношениях между человеком и миром. Метафора реализует концепции человека как центра восприятия мира.

Ключевые слова: коммуникация, метафора, контекст, дискурс, концепт.

\section{Abstract}

This article is devoted to the study of persuasive communication in political discourse and its metaphorical features. The image of the political world created by man is initially anthropocentric: this world is built in the mind of a person who is in the conceptualization of political realities on his ideas about the relationship between man and the world. The metaphor realizes the concept of a person as a center of perception of the world.

Keywords: communication, metaphor, context, discourse, concept.

Как уже упоминалось ранее, много научных трудов посвящено исследователями персуазивной коммуникации.

Термин «персуазивная коммуникация переводится как «внушение», «пропаганда. Но до сих пор не получен ответ на вопрос, где проходит линия разграничения между понятиями «речевое воздействие». Все вышеназванные типы общения являются средствами языковой манипуляцией в процессе которого происходит по мнению Х. Грюнерта «ментальнокоммуникативное взаимодействие партнеров по общению, при котором адресат пытается повлиять на адресата и заставить его действовать» [31, с.67].

Данный факт показывает, насколько сложно провести четко определенное разграничение между вышеназванными терминами, но для достижения поставленной цели нашего исследования мы попытаемся прийти к соответствующим определениям.

Американский исследователь Г. Джоуетт считает, что понятие «пропаганда» является ментальной единицей коммуникации, а внушение — часть пропаганды. Коммуникация же, 
рассуждает далее Джоуетт, есть факт сближения, при котором отправитель информации и получающий ее стремятся поделиться ею [6, с.50].

Очень часто способ убеждения и пропаганда используются в одном и том же смысле, и понимаются как одно и то же. Это явление происходит не без причины, так как эти два типа общения служат способами речевой манипуляции.

В модели коммуникации убеждение понимается как способ влияния на общение, в котором выигрывают обе стороны, отправитель и потенциальный получатель определенного сообщения.

В пропагандистской теории по мнению Г. Джоуетта данные термины, используют и как информацию и как убеждение, «чтобы извлечь выгоду из X за счет Ү. Это не значит, что Y не может извлечь из этого пользу; это скорее означает, что Ү явно не показывает свои истинные намерения, следовательно, его информация обманчивая» [6, с.56].

Использование X является целевым, а использование Ү довольно случайным.

Г. Джоуетт определяет данное действие следующим образом: «убедительное действие понимается как попытка убедить других с помощью лингвистических и невербальных средств, изменив свою собственную точку зрения на рассматриваемый вопрос или основываясь на полученной информации получить и добиться желаемой цели» [6, с.59].

Известные ученые М. Роллоф и Г. Миллер различают три случая подобных реакций [37, c.98].

В первом случае у аудитории нет особого отношения к адресанту, все является для него новым и неизвестным. По мнению М. Роллофа и Г. Миллера, отношения отправителя информации и аудитории в данной ситуации похожи на отношения между учителем и его учениками [37, с.99].

Во втором случае аудитория положительно относится к намерению отправителя и такое ее отношение не меняется.

Третий случай на самом деле является самой большой проблемой для отправителя посланий, потому что его намерение состоит в том, чтобы заставить аудиторию отказаться от существующего отношения и принять другое. Это особенно трудно выполнить, так как получатели информации уже представляют собой определенную форму культуры и люди уже имеют в своей ментальной структуре установившиеся ментальные идеи. Это все предопределяет социальное поведение людей, и именно эти факты затрудняют им изменить свое отношение к получаемой информации.

Согласно научной гипотезе М. Роллофа и Г. Миллера, убеждение можно рассматривать как умственный процесс и в него вовлечены три основных элемента: интеллект, воображение и эмоции. Сочетание этих трех элементов дает разные выражения. Это означает, что отправитель сообщения должен не только убедить свою аудиторию интеллектуально, но и стимулировать его творческие способности и мотивировать его на дальнейшие действия.

Несмотря на то, что термины «убеждение» и «пропаганда» имеют нечеткие границы, в литературе часто предпринимаются попытки как-то их разделить.

Так, Роллоф и Миллер утверждают, что убеждение основано на обсуждении и тщательном рассмотрении вариантов и стремится найти лучшие решения самых сложных проблем, в то время как пропагандой, скорее всего, будут манипулировать.

Из вышесказанного следует вывод о том, что убеждение и пропаганду можно отделить только в области намерения, так как намерение - это тот сегмент коммуникации, который в значительной степени решает, каким образом сообщение должно быть «упаковано».

У этих двух авторов убеждение существенно не отличается от аргументации.

Нечто подобное можно найти и у других авторов, которые говорят о убедительном общении: убедительное общение - это попытка партнеров по общению достичь консенсуса между собой относительно их руководствующих принципов. 
Однако тот факт, что человек вступает в процесс общения, а, следовательно, и в убедительное общение, требует консенсуса по определенным социальным принципам между коммуникантами.

Конечно, нельзя заранее прогнозировать, как нужно прийти к этому консенсусу, который предлагается для достижения определенного результата различные возможности языковых и нелингвистических явлений.

В лингвистической литературе проводится различие между прямым и косвенным способами воздействия. Самым убедительным общением является тип косвенного языкового воздействия:

Таким образом стало ясно, что убеждение и пропаганда являются средствами языковой манипуляции, и они не могут быть строго разделены.

Как пропаганда, так и убеждение являются социально зависимыми, и в результате чего они могут принимать различные формы, в которых реализуются различные степени манипуляции.

Различные определения, упомянутые до сих пор, являются результатом различных аспектов этих двух типов общения, которые, в свою очередь, основаны на используемых в них стратегиях.

В предыдущих разделах исследования уже было сказано, что политическая коммуникация, и особенно то, что происходит в рамках предвыборных кампаний, характеризуется высокой степенью убежденности. В такой коммуникации важную роль играют Метафоры.

Концептуальные метафоры обладают свойством быть аспектом одного подчеркнуть некоторые факты и скрыть другие.

Это свойство вытекает из того факта, что регулярно существует несколько концептуальных метафор для ситуации / обстоятельства, так что опытный оратор может выбирать в соответствии со своим намерением.

Образ политического мира, созданного человеком, изначально антропоцентричен: этот мир строится в сознании человека, который находится в концептуализации политических реалий на своих представлениях об отношениях между человеком и миром. Метафора реализует концепции человека как центра восприятия мира.

Как утверждают исследователи, каждая метафора существует не для себя, а в определенном контексте, тексте, дискурсе. Метафора может быть понята получателем только в том случае, когда он по крайней мере, учитывает контекст, в котором это реализовано.

Известный русский лингвист В.А. Чудинов [21, с.59] рассматривает политическую метафору в дискурсе прежде всего, как исследование влияния различных языковых, культурных, социальных, экономических, политических и других факторов на национальные системы концептуальных политических метафор.

В своем исследовании концептуальных метафор в российской политике В. А. Чудинов отмечает, что основная цель речи политической агитации состоит в том, чтобы изменить представления реципиента о политической реальности на определенную «сверхконцептуализацию» политического мира. [21, с.60].

Одним из наиболее важных средств такой «сверхконцептуализации» является метафорическая модель, которая либо подчеркивает определенный аспект проблемы, делает ее более значимой или, наоборот, отвлекает внимание общества или делает невозможным конкретный вариант развития событий [21, с.64].

Дж. Лакофф справедливо утверждает, что метафора служит самым эффективным инструментом для манипулирования общественным сознание [9, с.59]

В частности, он говорит: «Наша обыденная понятийная система, с точки зрения того, как мы мыслим и действуем, суть метафорическая по своей природе» [9, с.9].

Неметафорическая мысль, согласно Лакоффу, возможна только когда мы говорим о физической реальности. Чем больше индивид абстрагируется, тем больше метафорических слоев требуется для выражения мысли. Однако люди не замечают эти метафоры по 
различным причинам. Например, одной из причин является тот факт, что многие метафоры стали «мертвыми», и сейчас мы уже не можем определить их происхождение. Ещё одна, более банальная причина заключается в том, что мы просто «не видим, что происходит» [по Лакоффу].

$$
* * *
$$

1. Верещагин Е. М., Костомаров В. Г. Язык и культура. - М.: 2000. - 120 с.

2. Габуниа 3.М., Улимбашева Э.Ю. Межкультурная коммуникация как миросозидающий факт языка: учеб. пособие по спецкурсу «Межкультурная коммуникация». - Нальчик, 2005. - 176 с.

3. Головлева Е.П. Основы межкультурной коммуникации/ Е.П. Головлева //М.: Феникс, 2008.

4. Научная библиотека диссертаций и авторефератов disserCat http://www.dissercat.com/content/mezhkulturnayakommunikatsiya-v-sisteme-sotsiologicheskogo-znaniya\#ixzz5W7prDoHm

5. Гришаева Л.И! Введение в теорию, межкультурной коммуникации- /Л.И. Гришаева. Воронеж : Воронеж, гос. ун-т, 2003: - 386 с.

6. Дэцзидэма Д., Будаева С. В. Язык как средство трансляции культуры в процессе межкультурной коммуникации // Гуманизация образования. - 2014. - № 6. - С. 51-55.

\section{Алимханова М.X. \\ Фразеологические единицы с антропонимом на немецком языке \\ ФГБОУ ВО «Чеченский государственный университет им. А.А. Кадырова»}

(Россия, Грозньй)

doi: 10.18411/trnio-12-2021-211

\section{Аннотация}

Данная статья посвящена изучению фразеологизмов с одним компонентом антропонимом в современном немецком языке. В немецком языке объем фразеологизмов с названиями невелик, но такие фразеологизмы все же привлекают внимание исследователей. Ассоциации, связанные с конкретным личным именем, определяют семантику фразеологизма, к которому оно принадлежит.

Ключевые слова: фразеология, антропонимы, онимы, единства, фольклор.

\section{Abstract}

This article is devoted to the study of phraseological units with an anthroponym component in the modern German language. In German, the volume of phraseological units with names is small, nevertheless, such phraseological units attract the attention of researchers. Associations that are associated with a particular personal name predetermine the semantics of the phraseology that it is part of.

Keywords: phraseology, anthroponyms, onyms, unity, folklor.

Фразеология - это раздел языкознания, в котором изучаются лексически устойчивые словосочетания, которые называются фразеологизмами или фразеологическими оборотами. Понятие фразеология восходит к греческому $\Phi \mathrm{PA} \Sigma \mathrm{E} \Omega$, что в свою очередь можно перевести как “говорю”, “сообщаю”. Швейцарский ученый Чарльз Балли считается основоположником фразеологии как самостоятельной дисциплины «Traite de stylistique francaise», которая вышла в свет в 1909 году. Однако, фразеология получила более детальное рассмотрение только в начале 40-х годов XX века в трудах советского лингвиста и литературоведа В. В. Виноградова (1977). Именно В. В. Виноградов впервые широко установил понятие фразеологии, дал первую классификацию и определил основные направления изучения фразеологии. После этого аналогичный опыт имел место в Европе, особенно в Германии, где влияние советской фразеологии было очень велико.

Частота использования личных имен как элементов фразеологических единиц зависит от языка: в болгарском языке, к примеру, они встречается чаще, чем в русском. В немецком языке объем фразеологизмов с именами невелик, тем не менее, такие фразеологизмы привлекают внимание исследователей [11, с. 58]. Суть таких фразеологизмов достаточно объяснима, так как здесь обнаруживается связь между фразеологизмом и тем или иным 